\title{
The significance and managerial challenges of virtual teamworking
}

\author{
Nora-Labiba AL ZAIN \\ The Bucharest University of Economic Studies, Bucharest, Romania \\ alzain.nora@gmail.com \\ Simona VASILACHE \\ The Bucharest University of Economic Studies, Bucharest, Romania \\ simona.vasilache@gmail.com \\ Cynthia Bianka INCZE \\ The Bucharest University of Economic Studies, Bucharest, Romania \\ incze_cynthia@yahoo.com
}

\begin{abstract}
Living in a world where technology has evolved in an alarming pace, the working structures have become more diverse adapting to this trend, and giving birth to virtual teams, thanks to the ITC tools that have broken the physical boundaries, allowing coworkers to connect from all corners of the world and construct together. The aim of the article is to enrich the effectiveness of virtual teams but also acknowledge the difficulties they may run into throughout their project completions. Mixed methodology was chosen for the study case, having the Romanian Tourism Heritage Federation members as the sample of the survey. The quantitative method was used to quantify the data offered by the surveyed candidates and offer a deeper insight, by collecting data regarding certain aspects of the candidate such as: age, education and experience level, online "literacy", size and role of the team member etc. and presented in a well-structured figure table. Whereas, the qualitative method concentrated on obtaining beneficial data regarding aspects as: cultural and technological barriers, trust and team commitment barriers along with social interaction ones, as well as leadership and team dynamics perspective. The findings of the research were gathered, interpreted and presented briefly, giving a comprehensive image of the "virtual team" nowadays, facing both fruitful and challenging traces in their working style.
\end{abstract}

Keywords: virtual teams, communication, ITC, culture, trust, leadership, tourism.

\section{Literature review}

Given the progressive de-centralization and globalization of economic activity, many organizations have responded to the constantly changing environment by introducing virtual work arrangements, in which members are geographically dispersed and organise their work preponderantly with electronic information and communication media tools). This trend was accelerated by the desire to speed up the communication process and by the rapid development of new communication technologies.

In recent years, companies have increasingly employed virtual teams as a mean of connecting and engaging geographically dispersed workers, lowering the costs associated with global collaborationand enabling greater speed and adaptability (Ferreiraa, 2012). Regardless of the increasing popularity of this new work arrangement, limited information is available about the management of virtual teams and the many potential challenges that come with planning, organizing, motivating, leading and controlling them. In order to obtain 
effective results from virtual teams, it is important to define what integrates a team and what makes it virtual. The concept of a "team" is described as a small number of people with complementary skills who are equally committed to a common purpose, goals, and working approach for which they hold themselves mutually accountable (Zenun et al., 2007). Virtual teams issue began being discussed in the context of scientific research together with the concept "knowledge worker" (introduced by Peter Drucker since 1980), term associated with modern organizations who have adapted their organizational and operational structure under the constraint of information and communication technology's development.

According to Ebrahim et al. (2009b) virtual teams evolved and established themselves on the basis of small temporary groups, geographically, organizational dispersed work groups and who may reside in different time zones and who manage their work with ITC tools. The concept of virtual team differentiates itself from the one of teleworker (human operator dispersed from the physical borders of the motherorganization). The teleworking is represented by the pool of activities done outside of the conventional workplace, having all the communication processes performed with the aid of information technologies. When several teleworkers are combined and there is one manager that has them as subordinates, this is called a virtual group. When the members of the previously mentioned virtual group collaborate in order to achieve a common purpose, it is called virtual team. When considering these various forms of virtual work, attention must be drawn also to the notion of virtual organization, whose structure has as main premise the group management and holds both a communication and information system (or a knowledge management system) highly connected with the cultural dimensions of the organization and which emphasizes the importance of knowledge management in obtaining the competitive advatange (Popescu, 2005). In what the virtual networks are concerned, these utilize a telecommunication public infrastructure (such as the Internet) in order to offer to geographically dispersed members or teams a secure access to information and their organization's network (Rouse, 2007).

Reaching a minimal consensus on the existing research literature, virtual teams are composed of 1) two or more members who 2) cooperate interdependently to accomplish common objectives while 3 ) at least one of the members performs at a distinct location, organization, or at a different time, taking advantage of 4) communication and coordination mostly based on information and technology media (email, fax, phone, video conference, etc.). Although there are extreme situations when all members of virtual teams are working from distinctive locations and make use only of modern technology tools, most of the virtual teams benefit from sort of face-to face interaction. Rather than making a clear distinction between a virtual and a traditional team, it would be more useful to acknowledge the dimension of relative virtuality and the challenges imposed by it.

\section{Methodology}

A mixed methodology was employed because it is challenging to be able to quantify the effects that working in a virtual team has on its members/leaders for the purposes of comparing it with traditional teams. Simultaneously, it is important to determine the extent to which this approach enables trust, open communication, reliability, knowledge sharing and most important efficiency, traits that are difficult if not impossible to otherwise 
quantify. In order to provide an extensive view of how relationships within the team are affected by this new form of grouping and the team dynamics that are behind, a mixed methodology can be easily justified.

Quantitative data was collected by means of a survey distributed to members of virtual teams working in the Romanian Tourism Heritage Federation, all of them being located/relocated in different countries for tourism purposed. The advantage of using a combined methodological approach was that quantitative results from the findings could be easily recognised initially and the qualitative ones provided supplementary and comprehensive evidence for the research conclusions. Lastly, the approach of content analysis was employed to study the qualitative data, aiming at identifying patterns by analysing subjective experiences and proposals for a wellfunctioning virtual team.

The use of an electronic survey gave participants time for thoughtful answers without having to share answers with an interviewer (Fowler, 2002). This flexible survey instrument had systematic questions beginning with nonintimidating questions used for demographics. The use of an electronic survey is justified by the need to allow subjects to fill in the form in an effective and efficient manner given by e-mail invitations, without constraints but also by the desire to make data collection easier. The single-option questions that helped contouring the subject's profile respecting the confidentiality of the data submitted.

The population sample included 40 Virtual Team members within one major tourism federation, which works on common projects with organizations from all over the world within this domain. The population researched reached a total number of 50 participants who were participating or have participated in virtual project teams and have previous knowledge or work experience in these remote arrangements belonging to the private sector, respectively to the Romanian Tourism Heritage Federation. Having different educational backgrounds, job levels, attitudes and perceptions, has provided a level of diversity to the study, especially culture variety. Furthermore, having some insights on the virtual team dynamics as it relates to culture differences, social process, information and technology communication, organizational behavior, team identity and trust provides a tool that could help better understand and improve relationships among team members.

\section{Results and discussions Quantitative findings}

The survey conducted had as participants employees of the tourism federation mentioned earlier in the paper. Neither job titles or gender was not disclosed since they were irrelevant for the research and might have increased the probability of biased results; yet a general categorization between members and leaders was made. In this case, the variables used for defining the profile of the interviewee were: age, gender, experience and education level, the leadership/membership role within the team, online "literacy", stage of the virtual project and size of the team in which he/she activates along with other relevant points summed up in table 1 found below.

Table 1. Variables used for categorizing the identities of the interviewee 


\begin{tabular}{|c|c|}
\hline Gender proportion $\rightarrow$ & $\begin{array}{ll}- & 68 \% \text { Males; } \\
\text { - } & 32 \% \text { Females } \\
\end{array}$ \\
\hline Age Variation: $23 \rightarrow 55 \mathrm{y}$ & Average age: 38 y \\
\hline Experience level measured in years $\rightarrow$ & Mean: 5.6/10 \\
\hline Education level $\rightarrow$ & $\begin{array}{l}\text { - } \quad 60 \% \text { Master's Degree; } \\
\text { - } \quad 34 \% \text { Bachelor's Degree. }\end{array}$ \\
\hline $\begin{array}{l}\text { Leadership /membership role within the } \\
\text { team } \rightarrow\end{array}$ & $\begin{array}{l}\text { - } \quad 64 \% \text { team member status; } \\
\text { - } 36 \% \text { leader status. } \\
\end{array}$ \\
\hline Openness to online communication $\rightarrow$ & $\begin{array}{l}\text { - } 64 \% \text { comfortable using media to communicate } \\
\text { with coworkers; } \\
\text { - } 36 \% \text { prefer the remote way. }\end{array}$ \\
\hline Virtual team or traditional team?! & $\begin{array}{l}\text { - } \quad 64 \% \text { prefer virtual team; } \\
\text { - } 36 \% \text { prefer traditional team. }\end{array}$ \\
\hline $\begin{array}{l}\text { Online "literacy" for } 3 \text { variables: social } \\
\text { networks, online shopping and using ITC } \\
\text { tools for daily activities }\end{array}$ & $\begin{array}{l}\text { ITC tools for daily activities is used often to very often } \\
\text { while the other two have a medium degree! }\end{array}$ \\
\hline $\begin{array}{l}\text { Size of the teams analysed and stage of } \\
\text { execution of the virtual team project } \rightarrow\end{array}$ & $\begin{array}{l}\text { Medium-to-large teams where the stage of execution for } \\
60 \% \text { of them is midway and } 14 \% \text { near completion. }\end{array}$ \\
\hline Frequency of interacting face-to-face & $\begin{array}{l}50 \% \text { rarely do, } 20 \% \text { never did and } 12 \% \text { met their co- } \\
\text { workers. }\end{array}$ \\
\hline $\begin{array}{l}\text { Most used online tool for communication in a } \\
\text { virtual team } \rightarrow\end{array}$ & $\begin{array}{l}\text { E-mail - } 46 \% \text { with existent collaborators and } 40 \% \\
\text { with new ones; } \\
\text { - Instant messaging - } 42 \% \text { with existent } \\
\text { collaborators and } 76 \% \underline{A V I D} \text { with new ones; } \\
\text { - Video-conferencing is a frequent method. }\end{array}$ \\
\hline Is trust important to a virtual team?! & $\begin{array}{l}54 \% \text { stated it is more important within a virtual team } \\
\text { while } 38 \% \text { stated to be the MOST IMPORTANT FACTOR! }\end{array}$ \\
\hline $\begin{array}{l}\text { Does cultural dimension interfere with the } \\
\text { success of the projects?! }\end{array}$ & $\begin{array}{l}60 \% \text { believe it does in a moderate-to-great extent, while } \\
20 \% \text { find it as a moderate influencer and } 16 \% \text { place the } \\
\text { most importance to this aspect! }\end{array}$ \\
\hline $\begin{array}{l}\text { Most preferred quality within a virtual } \\
\text { team?! }\end{array}$ & $\begin{array}{l}\text { 1. Team commitment; } \\
\text { 2. Intense participation; } \\
\text { 3. Innovative thinking; } \\
\text { 4. Creativity-LEAST appreciated. }\end{array}$ \\
\hline $\begin{array}{l}\text { What are the expectations from the } \\
\text { coworkers within a virtual team?! }\end{array}$ & $\begin{array}{l}\text { 1. Reliability; } \\
\text { 2. Knowledge-sharing; } \\
\text { 3. Precise and quick communication. }\end{array}$ \\
\hline $\begin{array}{l}\text { Assessing the goals of the remote colleagues } \\
\text { resulted in } \rightarrow\end{array}$ & $\begin{array}{l}\text { Gaining experience is the major goal, neglecting the } \\
\text { knowledge-sharing and good performance goal! }\end{array}$ \\
\hline $\begin{array}{l}\text { What factors were marked as the most } \\
\text { important to the team's efficiency and } \\
\text { performance?! }\end{array}$ & $\begin{array}{l}\text { - Equity in team members' efforts; } \\
\text { - Project management/leadership and benefits; } \\
\text { - Compensation\&appraisal. }\end{array}$ \\
\hline
\end{tabular}

\section{Qualitative Findings}

Source: Author's own research. 
Grouping the responses of the qualitative study, after its interpretation and analysis, had the advantage of displaying a simple and understandable synthesis but also held the limitation that comprehensive information could have been lost in the summary. The openended research question was expressed in the request: "Describe a well-functioning virtual team and the potential challenges that may be encountered." The goal of the qualitative analysis was to compare and evaluate the results by sections in order to see if there were patterns or themes associated when discussing about the challenges imposed by virtual teams and make further recommendations for the organization that served as case study.

\section{Cultural differences barriers}

Response sample: Managing cultural differences is the key to success. The only obstacle I met was due to interpretations of cultural cues since we all perceive or interpret something differently based on own cultural experiences.

Virtual teaming brings multiple cultures working at the same table. Some colleagues may be more indirect in the way they communicate or on the contrary, direct communicators (especially those belonging to low-context cultures), may focus on sharing just the facts, which will leave high-context communicators feeling under-informed. The majority of the respondents felt the urge to become aware of their co-workers' cultural traits and expressed their need to be trained on cross-cultural communication and negotiation sincea great extent of communication difficulties, misunderstandings, lack of cohesion and increased conflict is due to cultural dimension's effect on the individual behavior (both direct and indirect, through perceptions related to peers' cultures). Once team members are aware of their enculturation and how it affects their decision making, they are able to understand other cultures and communicate with their teammates more effectively and this is what both parties need.

2. Trust and team commitment barriers

Response sample: We work better with those we trust, either it is a traditional team or a virtual one. Members should always be kept updated with their colleagues' daily tasks in order to avoid perceptions of unequal efforts.

The great majority of respondents emphasized identity and trust as factors that would improve overall team performance. This idea is fostered by the quantitative analysis performed based on the survey results, which showed that for them, trust is important to a great extent when performing in a virtual team. Still, trust is a real challenge within a virtual environment where members are dispersed and therefore lack the physical and visual interaction. And body language cannot play its role because it does not exist or is reduced at minimum and many of the basic cues about personality and social image we are accustomed to in the face-to-face setting are absent. By assessing the level of integrity and team commitment, it was revealed that co-workers do not meet their agreed commitments or respect deadlines since they are frequently ignored being much easier to ignore emails/phone calls received instead of physical presence. They also suggested that by devising a common system of keeping the team members up-to-date with the work activities done by their virtual colleagues in order to complete the task is a key-solution to trust enhancement. 


\section{Social interaction barriers}

Response sample: In a well-functioning virtual team, members are proactive, open-minded and eager to share knowledge. They are also good at understanding personality and communication style of their peers.

When considering social interaction challenges, the participants' responses revealed that face-to-face interaction still has an important role in the overall team performance. Even if it is not feasible for virtual team members to meet physically, the results showed that at least one initial face-to-face interaction is required to associate a presence to your virtual collaborator. Though the participants accepted the fact that team arrangements have evolved together with technological developments, they suggested informal strategies (informal meetings, chats, phone discussions, pictures sharing, outdoor activities) to improve relationships among team members. In addition, reliable social interactions exists when members find the balance between what to demand explicitly in the virtual communication and what to ask for, by offering and demanding equally intense participation, open communication and knowledge-sharing which results in a good independent work ethics.

4. Technology-based barriers Response sample: (...) using Technology has certainly improved work efficiency.

Information technology and communication tools (ITC) are the key components of a successful virtual team. They tend to become the favorite mechanism for integrating and distributing knowledge across organizations and their members. Yet, how to effectively use ITC tools still represents a challenge for virtual team members. Misunderstandings associated with technology availability and disponibility, as well as unmatched technology between members of the same team were the leading complaints among the respondents.

5. Leadership and management challenges

Response sample: (...)if every member of the team knows his job role and attributions, knows also the end result and works towards achieving it, then every virtual team will be a well-functioning one.

Participants stated that they need precise team structure and status reporting, that they need to be clear $100 \%$ with deliverables, purpose and execution methodology. But this is particularly hard whenmost workers are part of multiple teams and these teams form and reform continuously. This brings the challenge of having multiple reporting relationships with different management or leadership across the organization. Team leadership should assign members with established roles and responsabilities, based on their specific knowledge, skills and technology readiness. Clarifying responsabilities would translate into a higher commitment to deadlines and deliverables, an increase in overall trust and initiative towards future activities. Team leaders should promote interdependence and independency within the team and make sure everyone knows his input/contribution to the project is valued and they are important wheels in the machinery called team.

Leaders also need to handle conflict management which can escalade quite rapidly in a virtual team and if properly managed, conflict in a virtual team environment can enable brain storming and formation of new approaches and solutions. If it is ignored, it will affect 
team's cooperation and trust level and hinder its effectiveness. Conflicts within virtual teams have a great impact on schedule management. A need for consistent trainings on how to manage virtual teams was requested as well by team leaders.

6. Team dynamics challenges

Response sample: Virtual teams are efficient when members are disciplined.

PICBE | 31

After carefully analyzing the responses, it was more than obvious that people have different insights and understand virtual team dynamics in different ways. To begin with, time management is one of the issues but not necessarily a drawback, as it allows "workingaround-the-clock", meaning that team members can allocate their work-in-progress to other colleagues in different time zones. On the other hand, different time zones can impose challenges when there is a need for meetings (conferences). Schedule variation is very common in virtual projects' context so work agenda should be carefully managed and all other work-activities scheduled depending on the virtual meeting's priority. Attention must be paid also to the day-of-the-week or national holidays since Monday in one time zone may not be Monday in other parts of the world.

Another key point is the tasks prioritization, many respondents feeling that, due to the great level of virtuality, collaborators are more prone to distractions, are trying to accomplish multiple unrelated tasks and neglect their assumed responsabilities. Related to this issue are also the participants" opinions that interests of their virtual peers are not alligned to theirs or the ones of the organization they serve. If all the above would be taken into consideration, it can be assumed that organizational and cross-organizational virtual teams would be utilized at their full potential, which is boundless.

\section{Conclusions}

Virtual teams have become more and more popular in a world where technology cannot let us part anymore and there is a certain need to state their effective importance in today's world. The study case chosen has used a mixed methodology in order to obtain clearer and more efficient results in describing the bright and dark sides of the "virtual team" concept.

The quantitative analysis tested several tests of hypothesis and provided insights on how the overall team performance is affected by factors such as frequency of face-to-face meetings, team size, trust level, cultural differences, information and technology tools availability and complexity, perceptions that team members hold about their colleagues. This method was supplemented by the qualitative analysis of the resposens that had to be interpreted and reduced in order to display a simple and understandable synthesis about the main challenges that sustain virtual teams. The concept of virtual teams is an emergent one. Like most new phenomena in the era of change, the issues surrounding the setting up and running of these groups is in a state of transition and evolution. The research literature does not offer a fixed definition about what a virtual team is but what is certain is the fact that virtual teaming is still linked to the traditional team.

According to the results of the qualitative study, in a well-functioning team, individuals are able to work better together if they are culturally sensitive so special attention should be paid to this fact. Trust and team commitment were confirmed as being the main factors that could improve overall team performance. Regarding the technology functionalities, findings revealed that misunderstandings associated with technology 
availability, disponibility and syncronisation can be avoided by employing a complex IT infrastructure and provide the necessary training on it. Taking a look at management and team leadership, they must position themselves to handle team challenges by providing precise ierarchical team structure and status reporting, assigning members with roles and responsabilities and clarrify them, promoting both interdependence and independency within the team and handling conflict management.

PICBE $\mid 32$

Taking all into consideration, findings of this paper aim at filling a gap in the virtual team behavior analysis and should raise some question marks both to practitioners and the scholars in the field. Primarily, the great benefit of the study is the fact that it clearly demonstrated how overall team performance in a virtual environment is influenced by different variables. On a secondary level, for the analyzed population, the qualitative results surfaced that dimensions such as communication, trust, culture, knowledge-sharing, awareness of team colleagues' goals and certain behaviors preferred should be considered when performing in a global virtual environment in any domain.

\section{References}

Ale Ebrahim, N., Ahmed, S., Taha, Z. (2009). Virtual teams: a literature review. Australian Journal of Basic and Applied Sciences, 3(3), 2653-2669.

Bell, B., S.. Kozlowski, S.W. J. (2002). A Typology of Virtual Teams: Implications for Effective Leadership. Group \& Organization Management, 27, 14-49.

Beranek, P., M ., Martz, B., (2012). Making virtual teams more effective: improving relational links. Team Performance Management, 11.5/6, 200-213.

Bergiel, B., J., Bergiel, E., B ; Balsmeier, P., W., (2006). The Reality of Virtual Teams. Competition Forum, 4(2), 427-432.

Brunelle, E. (2012). Virtuality in Work Arrangements and Affective Organizational Commitment. International Journal of Business and Social Science, 3, 56-62.

Bryman, A., Bell, E. (2011) Business Research methods. Oxford: Oxford University Press, London.

Cascio, W.F. (2000). Managing a virtual workplace, Academy of Management Executive, $14(3), 1-88$.

Davison, S.C., Hambrick, D.C., Snell, S.A., Snow, C.C. (1996). Use transnational teams to globalise your company. Organizational Dynamics, 24(4), 50-67.

Duarte, L. D., (2006). Mastering Virtual Teams: Strategies, Tools, and Techniques That Succeed, 3rd ed., San Francisco, Jossey-Bass.

Dube, L. (2002). The Multi-Faceted Nature of Virtual Teams. International Journal of Managing Projects in Business, 1, 1-39.

Eissa, G., Fox, C., Webster, B. D., Kim J. (2012). A Framework for Leader Effectiveness in Virtual Teams. Journal of Leadership, Accountability and Ethics, 9(2), 11-22.

Ellemers, N., D. de Gilder, Haslam, S., A., (2004). Motivating Individuals and Groups at Work: A Social Identity Perspective on Leadership and Group Performance. Academy of Management Review, 29, 459-478.

Heller, R.,Laurito, A., Johnson, K.,Martin, M.,Fitzpatrick,R.,Sundin,K. (2010). Global Teams: Trends, Challenges and Solutions. Cornell Center for Advanced Human Resource Studies (CAHRS), New York, accessed online on 3th of April 2014. 
Hooijberg, R., Choi, J. (2000). Which leadership roles matter to whom?: An examination of rater effects on perceptions of effectiveness. Leadership Quarterly, 11(3), 341-364.

Kahai, S., Sosik, J., Avolio, B. (2003). Effects of leadership style, anonymity, and rewards on creativity-relevant processes and outcomes in an electronic meeting system context. The Leadership Quarterly, 14(4/5), 499-524.

Kayworth, T., Leidner, D. (2001). Leadership effectiveness in global virtual teams. Journal of Management Information Systems, 18(3), 7-40.

Montoya-Weiss, M., Massey, A.P., Song, M. (2001). Getting it together: temporal coordination and conflict management in global virtual teams. Academy of Management Journal, 44(6), 1251- 1263.

Oertig, M., Buergi, T. (2006). The challenges of managing cross-cultural virtual project teams. Team Performance Management, 12 (1/2), 23-30.

Popescu, C. (2005). Managementul cunostintelor in organizatiile virtuale, Annals of Oradea University, Fascicle of the Management and Techonological Engineering.

Powell, A ., Piccoli, G., Ives, B. (2004). Virtual teams: a review of current literature and directions for future research. The data base for advances in information systems, $35,6-36$.

Saunders, C. S. (2000). Virtual teams: Piecing together the puzzle, Cincinnati, OH: Pinnaflex.

Sivunen, A., (2006). Strengthening Identification with the Team in Virtual Teams: The Leaders" Perspective. Group Decision and Negotiation, 15, 345-366.

Snellman, C., L., (2014). Virtual Teams: Opportunities and challenges for E-leaders. Procedia - Social and Behavioral Sciences, 110, 1251-1261.

Van der Smagt, T. (2000). Enhancing virtual teams: social relations vs. communication technology. Industrial Management and Data Systems, 100(4), 148-56.

Zenun, M. M. N., Loureiro, G., \& Araujo, C. S. (2007). The Effects of Teams' Co-location on Project Performance. In Complex systems concurrent engineering (pp. 717-726). Springer, London. 